\title{
Correlational Study of Breast Cancer with Age, Marital and Socio-Economic Status in Women Using Clinical Data from Selected Hospitals in Southern Nigeria
}

\author{
Kennedy Irikefe Ekerikevwe ${ }^{1}$, Anthony K. Odior ${ }^{2}$ \\ 1,2Department of Statistics, School of Applied Sciences \& Technology, Delta State Polytechnic, Otefe- \\ Oghara, P.M.B. 03, Oghara, Delta State, Nigeria \\ E-mail: kennedyekerikevwe@gmail.com
}

\begin{abstract}
:
Cancer, also called malignancy, is an abnormal growth of cells. There are more than 100 types of cancer, including breast cancer, skin cancer, lung cancer, colon cancer, prostate cancer, and lymphoma. The morbidity of breast cancer has eaten up lots of women in the society today. This study, therefore, attempts to examine the relationship between the clinical episodes of breast cancer with age, marital and socio-economic status in women using data from selected hospitals in southern Nigeria. Reviews of medical records of 100 women with breast cancer from four randomly selected public hospitals in the southern part of Nigeria were made. The clinical episode of breast cancer of the 100 patients in the four hospitals were observed and documented for statistical analysis. The data collected include the bio-data, age, marital and socio-economic status of patients with breast cancer. The results of the Pearson's correlation show that breast cancer is highly correlated with marital status, positively related with the present age of attack, negatively correlated with age at first birth and negatively correlated with women socioeconomic status. The result collaborates a previous study made by Halabi and Bondy (2014). The study concluded that age and marital status are major risk factors of incidence of breast cancer among women in southern Nigeria. The study therefore recommends that there should be a better focused health education, marriage before sex orientation and other preventive strategies for Nigerian women and that the National Health Insurance Scheme (NHIS), should as a matter of urgency, incorporates women with breast malignancy into the scheme for adequate care, palliatives and stimulus. There should be adequate awareness about the disease and access to health care facilities for women in southern Nigeria to carry out routine check for lumps in their breast.
\end{abstract}

Keywords:

morbidity; cancer; pearson correlation; risk factors; clinical episodes; age; random sample

\section{Introduction}

Breast cancer is an intricate turmoil caused by interactions of hereditary and environmental factors. The word "Cancer" is a broad term. It describes the disease that results when cellular changes cause the uncontrolled growth and division of cells. Cancer, also called malignancy, is an abnormal growth of cells. Throughout our lives, healthy cells in our bodies divide and replace themselves in a controlled fashion. Cancer starts when a cell is somehow altered so that it multiplies out of control. A tumor is a mass composed of a cluster of such abnormal cells. Kirtland (2006), explained that breast cancer claims the lives of many women because when all known risks factors and characteristics such as obesity, smoking, high fat diet and changes in life style are added together including genetics and family history, up to $50 \%$ of breast cancer remain unexplained. This makes the problem alarming and worrisome because the main cause of the disease could not been ascertained. Linked to this is the ignorance of women who believe that symptoms would normally accompany the emergence of breast 
cancer in individuals as it is the case in malaria and other related sicknesses. The contribution of risk factors such as race, socioeconomic status, lifestyle, reproductive factors, and diet to the morbidity and mortality arising from breast cancer has been acknowledged in various studies (Kirtland, 2006).

Breast cancer can occur in both men and women, but it's far more common in women. Signs of breast cancer may include a lump in the breast, a change in breast shape, dimpling of the skin, and fluid coming from the nipple, a newly inverted nipple, or a red or scaly patch of skin. Breast cancer is a major ailment that girls fear the most. It is so life threatening and several causes have been assumed by reports have shown that none of them is concrete enough to cause the occurrence of breast cancer. The World Health Organization (2012) reported that female breast cancer is a major global public health problem with an estimated 1,384,155 new cases worldwide and over 459,000 related deaths annually. In Nigeria, National Bureau of Statistics (2014) stated in their report that female breast cancer is recognized as major cause of morbidity and mortality with incidence rate ranging from 36.3 to $50.2 / 100,000$ live birth. Jemal et al., (2011) stated that the number of breast cancer cases is growing in developing countries and breast cancer is the most common diagnosed cancer in women with a geographical variation in occurrence. According to literatures, there are more than 100 types of cancer, including breast cancer, skin cancer, lung cancer, colon cancer, prostate cancer, and lymphoma. Symptoms vary depending on the type. Cancer management may include chemotherapy, radiation, and/or surgery.

\subsection{Statement of Problem}

Breast cancer is the second most prevalent cancer in the world and the most common cancer among women. Breast cancer persists as an international health burden despite advances in its early diagnosis, treatment and also increased knowledge of its established risk factors. The risk factors can be statistically modeled using multiple correlation analysis. This study, therefore, considers, age, marital and socio-economic status as risk factors and establish an empirical relationship between the risk factors and incidence of breast cancer among women in Southern Nigeria.

\subsection{Objectives of the Study}

The objectives of this study are as follows:

1. To examine the possible risk factors influencing the occurrence of breast cancer amongst women.

2. To identify the risk factors associated with the incidence of breast cancer, amongst women in southern Nigeria.

3. To provide an empirical evidence of the relationship that exist between breast cancer with age, marital and socio-economic status in women using clinical data from selected hospitals in southern Nigeria

\subsection{Significance of the Study}

The study on the risk factors of breast cancer among women is a very vital issue, as its findings will benefit health management in focusing on major risk factors related to the occurrence of the disease. The findings will also contribute to the body of knowledge on breast cancer among women (married and unmarried) in order for them to benefit on various ways of preventing the occurrence of breast cancer given any known risk factor noticed by them in their body. However, this study is limited in scope as it mainly focused on the occurrence of breast cancer among women in Southern Nigeria; therefore, our findings are open for further studies based on a wider scope of coverage. 


\section{Review of Literatures}

WHO (2014) ascertained that, in Nigeria, female breast cancer is recognized as major cause of morbidity and mortality with incidence rate ranging from 36.3 to 50.2/100,000 live birth. Kirtland (2006) conducted a study which shows that life time risk of this disease nearly tripled within 50 years as 1 in 20 women had it in 1960, 1 in every 7 in 1980. However, WHO (2004) documented that since 1987, breast cancer rates increased by $0.5 \%$ each year and between $85 \%$ and $90 \%$ of the cases cannot be attributed to inherited genetic predisposition. On the burden of cancer in Nigeria, Lambo (2007) explained that there is likely to be 100,000 new cases each year, and that by 2010 there may be 500,000 new cases. To understand the problem facing cancer patients in Nigeria, it is worthy of note that the survival rate for breast cancer in the Unites States of America is $85 \%$ while it is a dismal $10 \%$ in Nigeria. Durosimi (2004) reported a survival rate of $1.9 \%$ for Nigeria and over $50 \%$ for East Africa and other countries. The Lagos State Ministry of Health documented that the annual 15\% of the cases occur in women less than 30 years of age.

Shelps (2013) explains that the development of the human female breast begins during gestation but is not complete at the time of birth. Further development and differentiation of breast tissue occurs over time and especially in response to fluctuating estrogen and other hormonal signals beginning in puberty, continuing through the reproductive years, during pregnancy and lactation, and at menopause.
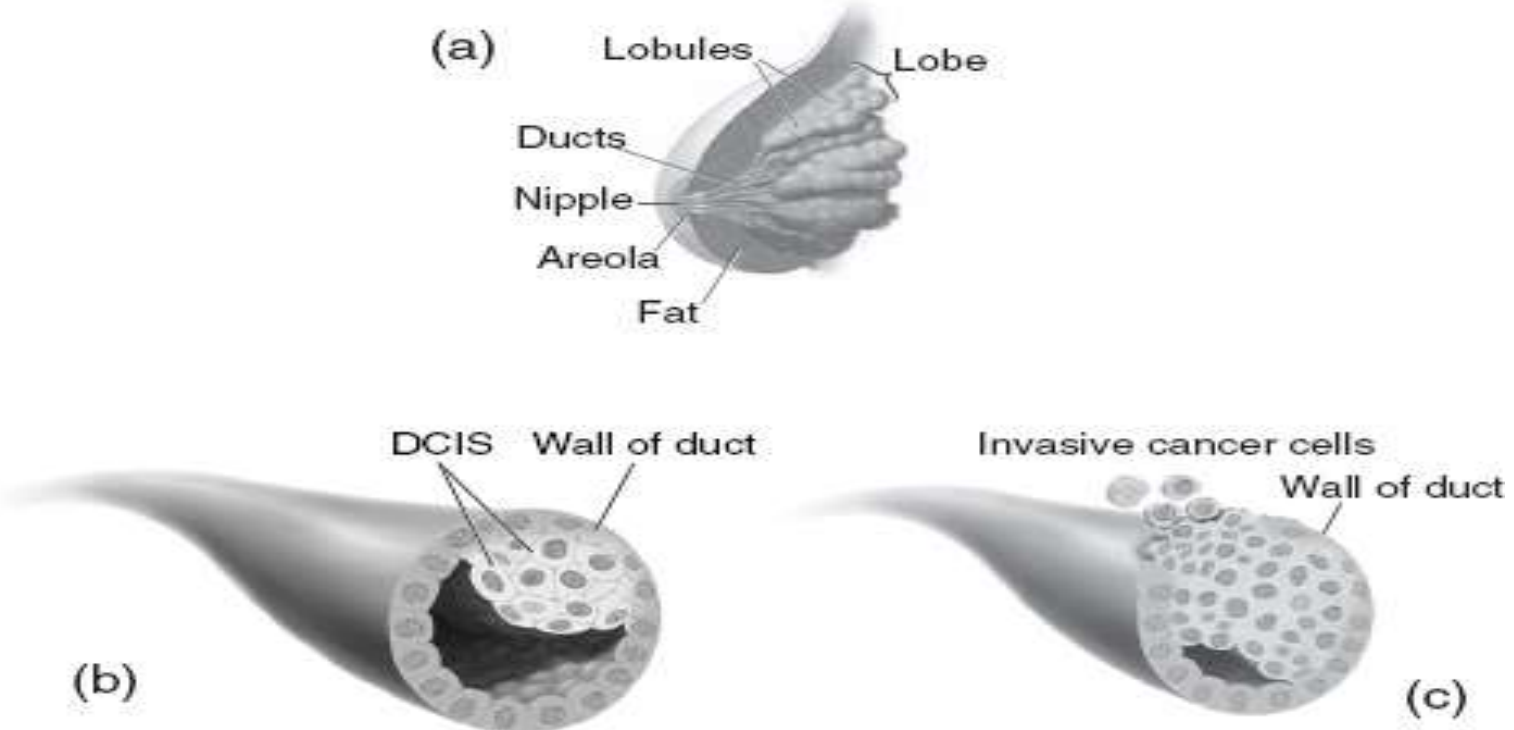

Figure 1. Schematic representation of

(a) The breast, showing lobules and ducts,

(b) Ductal carcinoma in situ (DCIS), and

(c) Invasive ductal cancer.

Source: Institute Of Medicine (2012) at https://www.nap.edu/read/13263/chapter/7\#241

Zhang (2016) on explaining the development of breast cancer stated that certain disruptions in the complex processes that govern the structure and function of breast tissue may set the stage for breast cancer. Some carcinogenic events occur spontaneously in the course of normal biological processes and others are triggered by external factors. Although the body has efficient protective responses, such as DNA repair and immune surveillance, that can reduce the effect of such events, these protective responses are not always successful. The interval between the earliest "event" and the detection of a cancer may span several decades. 
Edward (2009) stated that the actual cause of breast cancer is unknown but studies have implicated age, gender, heredity, reproductive factors, diet and anthropometric characteristics as possible etiological factors. While these factors may be at play in Nigerian women, it is important to note that there is considerable variation in the geographical, age, education and ethnic distribution of the disease attributed to environmental and genetic factors. This study is aimed at identifying risk factors for breast cancer in Nigerian women. Identification of these factors may enhance the ability to prevent the disease by permitting better focused health education and other preventive strategies. Halabi and Bondy (2014) discovered that many women reported that they did not think about the high risks involved in breast cancer since there were no signs and symptoms. To Hartge (2003), there are multiple factors working together to enhance the probability of developing breast cancer and contribute to the variability in incidence of the disease onset. The menace of breast cancer is influenced by early and late events in life, but the mechanism of differential susceptibility has not been fully explored which complicates the prevention procedures. Penhoet et al (2005) added that regardless of ethnic and racial origin, all females are at risk of having breast cancer but variations in its incidence among different populations suggest that etiological factors differ in their biological expression and thus have impact on the disease onset.

Patel et al (2018) studies the role of nutritional factors in pathogenesis of cancer. They noted that diet and nutrition are crucial factors throughout the complete life course in the promotion and upholding of good health and that the etiology and pathogenesis of cancer is a multifaceted interplay mechanism of genetic and environmental factors. They concluded that, though breast tumors may differ clinically and biologically by hormone receptor status and menopausal status, dietary factors have long been thought to play a major role in the development of breast cancer.

Aritonang et al (2019) carried out a study on related knowledge and support family mother pregnant women attitudes about prenatal care (ANC). The purpose of the study was to determine the mother's knowledge and family support for the attitudes of pregnant women regarding ANC in the work area of Gunung Anyar Public Health Center, Surabaya City. Using Chi Square test and confidence level of $90 \%$, they concluded that there is no relationship between maternal knowledge and family support with the mother's attitude about ANC.

Syawalina et al (2020) studies the education relation, number of children and acceptance of $\mathrm{KB}$ information with pregnancy due to unmet need $\mathrm{KB}$ in pregnant mother in Binjai Health Center City in 2019. They noted that one of the ways to suppress population is family planning through pregnancy control and regulation. The main purpose of their study was to analyze the relation of education, number of children and acceptance of family planning information with pregnancy due to unmet need for KB in pregnant women. They used a cross sectional sample of 113 pregnant women in December 2018 - August 2019. The data were collected by interview using a questionnaire. The results of the study using multiple logistic regression showed that respondents who had 1-2 children and did not receive family planning due to unmet need for birth control by $57.8 \%$. the suggested that health workers should pay more attention to those who have 1-2 children who are motivated to participate in the family planning program and ask pregnant women to ask health workers before using family planning tools as clearly as possible so that they are expected to be able to reduce the reason for unmet need for family planning.

Hidayati, et al (2020), conducted a study on correlation of fried snacks intake with free radicals and obesity in elementary school Children. They found that the increase in degenerative disease and obesity is mainly caused by lifestyle, eating pattern, and activities. The 
objective of this research was to find out the correlation of fried snacks intake with free radicals, and obesity. The research used quantitative method with cross sectional design. They used samples of 56 students of elementary school, taken by using purposive sampling technique. The result of Pearson correlation test showed that there was the correlation between fat nutrient intake in fried snacks and obesity $(p=0.012)$.

\subsection{Some Risk Factors of Breast Cancer among Women}

In the course of this study, questionnaires relating to the subject matter were distributed to some medical personnel using accidental sampling techniques, the results pointed that the following are the major risk factors related to the occurrence of breast cancer; these observed risk factor were therefore linked with existing literature as follows:

\section{a. Hereditary}

Oldenburg et al., (2007) in a study on possible risk factors among women stated that a family history of breast cancer is an established breast cancer risk factor. This risk factor represents both inherited genetic risks as well as environmental factors that may cluster in families. They added that on an overall, an inherited susceptibility to breast cancer contributes to about 10 percent of breast cancer cases, and in about 5 percent of breast cancer cases, this inherited susceptibility is attributed to mutation of genes. Mutations are high-penetrance mutations, meaning that women with these mutations have a very high lifetime risk of developing breast cancer. Narod and Offit (2005) estimated that hereditary to be at least 40 percent and possibly as high as 85 percent. However, these mutations are rare, with substantially less than 1 percent of women in most populations carrying them. In addition to increasing the risk of breast cancer for women, they also increase risk for male breast cancer. Families in which such mutations may be present may have multiple cases of breast cancer, occurring at younger ages and in multiple generations, and a family history of ovarian cancer.

\section{b. Reproductive Risk Factors}

A study on cancer prevalence by Boyd et al., (2010) suggested that several factors that are generally considered to be associated with increased risk for breast cancer. They includes having a family history of the disease, particular reproductive characteristics (e.g., earlier age at menarche, later age at menopause, later age at first live birth), and certain forms of benign breast disease, as determined by breast biopsies. Greater mammographic density, which reflects a higher proportion of connective and epithelial tissue in the breast, is a physiologic characteristic that is consistently associated with increased risk of breast cancer. Studies in twins indicate that it is a heritable trait.

In a review of epidemiologic studies, Bernstein, et al (2003) also found differences between African American and white women in reproductive risk factor profiles. Bernstein et al. (2003) found that, compared to African American women, white women are about twice as likely to breastfeed, and their cumulative time spent breastfeeding is longer. However, some of the associations between reproductive factors and breast cancer risk may be stronger for white non-Hispanic women than for women of other races and ethnicities. Hines and Colleagues (2010) found that among premenopausal Hispanic women, only late age at first birth had a statistically significant association with increased risk of breast cancer. Reproductive factors were not associated with breast cancer risk among postmenopausal Hispanic women.

\section{c. Menopause and Older Ages}

According to the study carried out by Olopade (2004) age is found to be a causal factor for prevalence of diseases. Gender (being female or male) could trigger the prevalence of a disease due to changes in the components of the body. Most breast cancers are 
diagnosed in menopausal women. McCready et al., (2010) stated that menopause is characterized by a cessation of ovarian hormone production, and subsequently, the end of a woman's menstrual cycles. The loss of estrogen and progesterone production coincides with a process known as lobular involution, or the reduction of both number and size of lobules in the breast. They added that the number of epithelial cells in the breast expressing estrogen receptors increases significantly, and the interlobular stroma of the breast are increasingly replaced by adipose tissue. They further explained that at this stage of life, breast tissue has also been influenced by the cumulative opportunity for previous exposures to endogenous and exogenous factors to generate compromised cells.

Chlebowski et al., (2010) in their study on breast cancer trend in Bangkok stated that the risks decline rapidly on withdrawal of combined hormone therapy in the postmenopausal period. While the mechanism for the increased risk is not known in detail, it is thought that hormone therapy may be causing proliferation of cancer stem cells. They added that in the absence of hormonal stimulus, other regulatory processes in the body may be able to inhibit the progression of tumorigenesis or expansion of an existing tumor.

\section{d. Socio-Economic Status}

Steve (2009) stated that both individual factors and environmental factors contribute to the risk of cancer and the prognosis for affected patients. In cancer epidemiology, the impact from socioeconomic status (SES) on incidence rate and prognosis is increasingly recognized. High SES has been linked to a higher risk for breast cancer and malignant melanoma; whereas low SES is associated with adverse prognosis in for example stomach cancer, lung cancer, prostate cancer and ovarian cancers. He explained also that incidence, case fatality and mortality rates are affected by both illegitimate factors of inequality, 'circumstances' and legitimate factors of inequality, 'effort'. Circumstances are factors exogenous to the person, including age, access to health care and childhood SES, while efforts are factors that can be influenced by the person, including lifestyle factors such as smoking, alcohol use and physical activity. A policy of equal opportunity requires an understanding of how circumstance and effort contribute to observed inequality. It is especially hard to identify factors of effort and how these are influenced by circumstance. Ogundipe and Obinna (2008) believe that diet and environment which arose as a result of lifestyle or westernization and lack of awareness, access to health care facilities, no plan for such diseases in the National Health Insurance Scheme (NHIS), lack of empowerment of women, bad economy and other social factors are responsible for prevalence diseases. In addition, inadequate clinical services for life threatening diseases and poor distribution of medical personal protective equipment (MPPE) assist in prevalence.

This study, therefore, considers, age, marital and socio-economic status as risk factors and establish an empirical relationship between the incidence of breast cancer and these three factors using reviews of medical records of 100 patients with breast cancer from four randomly selected public hospitals in the southern part of Nigeria.

\section{Research Methods}

\subsection{Target Population}

The population of interest in this study consists of all married women who are victim of breast cancer epidemic in the Southern part of Nigeria. To this end, the study considers this population quite a large one and almost practically impossible to cover within the period that the investigation was carried out. 


\subsection{Sample and Sampling Technique}

The study, with the constraint of time and resources, considered the selection of the population fraction (sample) that will represent the entire population. The sample selection was random through the use of the multi-stage sampling approach. The states in southern Nigeria includes: Akwa Ibom, Bayelsa, Cross River, Delta, Edo, and Rivers. The first stage of the sampling used the purposeful sampling to select two states due to proximity (Delta and Edo). The second stage of the sampling process used the simple random approach to select two local government areas each from both states, i.e. (Ughelli North and Ethiope West LGAs from Delta state while Oredo and Ikpoba Okha LGAs from Edo state. The third stage used the simple random sampling to select one hospital from each of the LGAs. In total, four different local governments from two different states in southern Nigeria were selected for this study. The hospitals selected for the study includes: General Hospital, Oredo; Central Hospital, Ikpoba Okha; Central Hospital, Ughelli; and Delta State University Teaching Hospital, Oghara, Ethiope West.

\subsection{Method and Source of Data Collection}

Reviews of medical records of 100 patients with breast cancer from four randomly selected public hospitals in the southern part of Nigeria (General Hospital, Oredo; Central Hospital, Ikpoba Okha; Central Hospital, Ughelli; and Delta State University Teaching Hospital, Oghara, Ethiope West). This clinical episode of breast cancer of the 100 patients in the four hospitals were observed and documented for statistical analysis. The data collected include the bio-data, age, marital and socio-economic status of patients with breast cancer to model the relationship between the risk factors and incidence of breast cancer amongst the women.

\subsection{Method of Data Analysis}

Consider $\mathrm{N}$ observed values of each of $\mathrm{n}$-variable. Theses $\mathrm{n} \times \mathrm{n}$ values may be tabulated in a double-entry table as follows:

$$
\left(\begin{array}{ccccc}
X_{11} & X_{12} & X_{13} & \ldots X_{1 N} \\
X_{21} & X_{22} & X_{23} & \ldots X_{21} \\
\ldots & \ldots & & \ldots \\
X_{n 1} X_{n 2} X_{n 3} & \ldots & X_{n N}
\end{array}\right)
$$

Where $X_{i k}$ is the $\mathrm{k}^{\text {th }}$ value of the $i^{\text {th }}$ variable. Using the $i^{\text {th }}$ variable as the dependent variable, the general relationship between the $\mathrm{n}$ variables may be expressed by

$$
X_{i}=a_{1} x_{1}+a_{2} x_{2}+\cdots+a_{i-1} x_{i-1}+a_{i+1} x_{i+1}+\cdots+a_{n \ldots \ldots .} \ldots \text { (1) }
$$

Where $a_{i}$ is the general parameter which is to be determined empirically; $x_{i}=X_{i}-M_{j}$

$M_{j}$ is the arithmetic mean of the $j^{\text {th }}$ variable

By the method of the least squares, the constants of equation 1 above must satisfy the normal equations:

$$
\sum x_{i} x_{j}=N r_{i j} \sigma_{i} \sigma_{j}
$$

Where $r_{i j}$ is the coefficient of correlation between the $i^{\text {th }}$ and $j^{\text {th }}$ variables, $\sigma_{\bar{i}}$ is the standard deviation of the variable. 
For a multiple correlation coefficient, we use the formula as put together by equation 1 and 2:

$$
\begin{aligned}
& r_{x_{1} x_{2}, x_{1}}=\sqrt{\frac{r_{12}^{2}+r_{13}^{2}-2 r_{12} r_{13} r_{23}}{1-r_{23}^{2}}} \\
& r_{12}=\frac{n \sum x_{1} x_{2}-\sum x_{1} \sum x_{2}}{\sqrt{\left(n \sum x_{1}^{2}-\left(\sum x_{1}\right)^{2}\right)\left(n \sum x_{2}{ }^{2}-\left(\sum x_{2}\right)^{2}\right)}} \\
& r_{13}=\frac{n \sum x_{1} x_{3}-\sum x_{1} \sum x_{3}}{\sqrt{\left(n \sum x_{1}{ }^{2}-\left(\sum x_{1}\right)^{2}\right)\left(n \sum x_{3}{ }^{2}-\left(\sum x_{3}\right)^{2}\right)}} \\
& r_{23}=\frac{n \sum x_{2} x_{3}-\sum x_{2} \sum x_{3}}{\sqrt{\left(n \sum x_{2}{ }^{2}-\left(\sum x_{2}\right)^{2}\right)\left(n \sum x_{3}{ }^{2}-\left(\sum x_{3}\right)^{2}\right)}}
\end{aligned}
$$

Where $\mathrm{r}=$ correlation coefficient, $\mathrm{n}=$ number of observational data, $\mathrm{X}_{1}=$ number of married women with breast cancer, $\mathrm{X}_{2}=$ number of single women with breast cancer, $\mathrm{X}_{3}=$ total number of women with breast cancer.

For Test of association, we make use of the test statistic:

$|t|=r \sqrt{\frac{n-2}{1-r^{2}}}$

To test the confidence of the correlation coefficient:

$Z_{r} \pm Z_{\frac{a}{a}}\left(\sigma_{z}\right)$

Where $Z_{r}=\frac{1}{2} \ln \frac{1+r}{1-r}$,

$$
\begin{gathered}
\sigma_{z}=\sqrt{\frac{1}{n-3}} \\
Z_{0.5-0.025}, \\
Z_{0.475}=1.96
\end{gathered}
$$

\section{Discussion}

Table 1. Distribution of patients' age at first birth

\begin{tabular}{|l|l|l|l|l|l|l|}
\hline Age at first birth & 2014 & 2015 & 2016 & 2017 & 2018 & Total \\
\hline $15-24$ & 10 & 5 & 6 & 5 & 4 & 30 \\
\hline $25-34$ & 13 & 10 & 10 & 7 & 6 & 46 \\
\hline $35-44$ & 5 & 5 & 2 & 2 & 1 & 15 \\
\hline $45-54$ & 4 & 2 & 1 & 1 & 1 & 9 \\
\hline $55+$ & 0 & 0 & 0 & 0 & 0 & 0 \\
\hline
\end{tabular}

Source: Field survey, 2019

Table 2. Partial Correlation between Cancer among Women with Age and Socio-Economic Status

\begin{tabular}{|l|c|c|c|}
\hline Control Variables & $\begin{array}{c}\text { Number of } \\
\text { Patients } \\
\text { Working }\end{array}$ & $\begin{array}{c}\text { Distribution of } \\
\text { Patients' Age At } \\
\text { First Birth }\end{array}$ & $\begin{array}{c}\text { Age } \\
\text { Distribution of } \\
\text { Patients }\end{array}$ \\
\hline Married Number Of Correlation & 1.000 & -.803 & .590 \\
\hline
\end{tabular}




\begin{tabular}{|c|c|c|c|c|c|}
\hline \multirow[t]{3}{*}{$\begin{array}{l}\text { Women } \\
\text { With } \\
\text { Cancer (Y) }\end{array}$} & $\begin{array}{l}\text { Patients } \\
\text { Working }\left(\mathrm{X}_{1}\right)\end{array}$ & $\begin{array}{l}\text { Significance } \\
\text { (2-tailed) } \\
\text { Df }\end{array}$ & 0 & 197 & .013 \\
\hline & $\begin{array}{l}\text { Distribution } \\
\text { Of Patients' } \\
\text { Age At First } \\
\text { Birth }\left(\mathrm{X}_{2}\right)\end{array}$ & $\begin{array}{l}\text { Correlation } \\
\text { Significance } \\
\text { (2-tailed) } \\
\text { Df }\end{array}$ & & 1.000 & $\begin{array}{r}-.756 \\
.244 \\
2\end{array}$ \\
\hline & $\begin{array}{l}\text { Age } \\
\text { Distribution } \\
\text { Of Patients } \\
\left(\mathrm{X}_{3}\right)\end{array}$ & $\begin{array}{l}\text { Correlation } \\
\text { Significance } \\
\text { (2-tailed) } \\
\text { Df }\end{array}$ & & & 1.000 \\
\hline
\end{tabular}

Table 2 above indicates the relationship between incidence of breast cancer with women marital status, their age at first birth, their age at cancer attack, and their socioeconomic status (working class level). The result $r_{y x_{1}, x_{2} x_{g}}(-0.803)$ shows a strongly negative correlation with $\mathrm{p}$-value of $0.197>0.05$. This result shows that breast cancer is negatively correlated with women socio-economic status with no significantly relationship. Also, incidence of cancer among women with respect to the age of cancer attack on patients and their age at first birth $\left(r_{y x_{2} x_{1} x_{a}}\right)$ is moderately positive $(0.590)$ with a $\mathrm{p}$-significant value of $0.013<0.05$. This result shows that breast cancer among the women is significantly related with their present age and uncorrelated with their age at first birth.

Table 3. Simple Correlation between Breast Cancers among Women with Marital Status

\begin{tabular}{|ll|r|r|r|}
\hline & $\begin{array}{c}\text { Married } \\
\text { Women } \\
\text { With Cancer }\end{array}$ & $\begin{array}{c}\text { Unmarried } \\
\text { Women } \\
\text { With Cancer }\end{array}$ & $\begin{array}{c}\text { Total Number } \\
\text { of Women With } \\
\text { Cancer }\end{array}$ \\
\hline Married Women & Pearson Correlation & 1 & $.931^{*}$ & -.534 \\
With Cancer $\left(\mathrm{X}_{1}\right)$ & Sig. (2-tailed) & 5 & .022 & .036 \\
& $\mathrm{~N}$ & & 5 & 5 \\
\hline Unmarried & Pearson Correlation & & 1 & .693 \\
Women With & Sig. (2-tailed) & & 5 & .023 \\
Cancer $\left(\mathrm{X}_{2}\right)$ & $\mathrm{N}$ & & 5 \\
\hline Total Number of & Pearson Correlation & & & 1 \\
Women With & Sig. (2-tailed) & & & 5 \\
Cancer $\left(\mathrm{X}_{3}\right)$ & $\mathrm{N}$ & & & \\
\hline
\end{tabular}

*. Correlation is significant at the 0.05 level (2-tailed).

Table 3 presents the relationship between the occurrences of breast cancer among women with their marital status. The results shows $\left(r_{x y}=0.693\right)$ between unmarried and $\left(r_{x y}=-\right.$ $0.534)$ between the married. These results show that the incidence of breast cancer has a positive relationship with the unmarried women and negative relationship with married women. These results may be linked to the study conducted by Halabi and Bondy (2014). Halabi and Bondy (2014) opined that a constant breast massage goes a long way in reducing the risk/chances of women having breast cancer among the married women. 


\section{Conclusion}

This study used multiple correlations to investigate the relationship between breast cancer occurrences with age, marital and socio-economic status of women in Southern part of Nigeria. The study made used of the clinical episodes of 100 randomly selected women with cancer attack from Delta and Edo state, southern Nigeria. The findings of the study reported that breast cancer is highly correlated with marital status, positively related with the age of attack and negatively correlated with age at first birth. The results collaborated with a previous study made by Halabi and Bondy (2014). The study, therefore, made the following recommendations:

1. There should be adequate clinical services for women with the life threatening diseases of breast cancer to reduce the mortality rate as a result of inadequate care for patients with the disease.

2. There should be adequate awareness about the disease and access to health care facilities for women to carry out routine check for lumps in their breast.

3. There should be a better focused health education and other preventive strategies for Nigerian women

4. Husbands of married women should be encouraged to take continuous grasp of their wives' breast to help reduce the risk of having breast lumps.

5. The National Health Insurance Scheme (NHIS), should as a matter of urgency, incorporates women with breast malignancy into the scheme for adequate care, palliatives and stimulus.

\section{References}

Aritonang, D. V., Adiwijaya, S., Wulandari, A. and Nyoman, A. D. (2019). Related Knowledge and Support Family Mother Pregnant Women Attitudes About Prenatal Care (ANC). Budapest International Research in Exact Sciences (BirEx) Journal, Volume 1, No 3.

Boyd, N. F., Dite, J., Stone, A., Gunasekara, D. R., and English, M. R. (2010). Heritability of mammographic density, a risk factor for breast cancer. N Engl J Med 347(12)

Chlebowski, N., Martin, M., Bronskill, M. J., Yaffe, N., and Minkin, S (2010).Breast tissue composition and susceptibility to breast cancer. J Natl Cancer Inst102 (16)

Edward, P. (2009). Changing incidence of breast cancer in Japanese-American women. J Natl Cancer Inst 51(5)

Halabi, N. and Bondy, Q. (2014). Progress in cancer screening over a decade: Results of cancer screening from the 1987, 1992, and 1998 National Health Interview Surveys. J Natl Cancer Inst 93(22)

Hartge, L. (2003). Descriptive analysis of estrogen receptor (ER)-negative, progesterone receptor (PR)-negative, and HER2-negative invasive breast cancer, the so-called triplenegative phenotype: A population-based study from the California Cancer Registry. Cancer 109(9).

Hidayati, U. Siagian, A. and Sudaryati, E. (2020). Correlation of Fried Snacks Intake with Free Radicals and Obesity in Elementary School Children. Budapest International Research in Exact Sciences (BirEx) Journal, Volume 2, No 1.

Institute Of Medicine (2012). Breast Cancer and the Environment: A Life Course Approach. Washington, Dc: The National Academies Press at https://www.nap.edu/read/13263/chapter/7\#241

Jemal, S., Iglehart, H. and Miron, P. L. (2011). Gene expression profiling of NMU-induced rat mammary tumors: Cross species comparison with human breast cancer. Carcinogenesis 26(8) 
Hines, G., Anderson, W. F., Jatoi, J., and Rosenberg, P. S. (2010). Male breast cancer: A population-based comparison with female breast cancer. J ClinOncol28 (2):232-239.

Kirtland, N. (2006). Update on mammography trends: Comparisons of rates in 2000, 2003, and 2005. Cancer 117(10)

Lambo, H. (2007). Race, breast cancer subtypes, and survival in the Carolina Breast Cancer Study. JAMA 295(21)

McCready, D. F., Pooley, A. M., Dunning, P. D., Pharoah, D., Thompson, D. G., Ballinger, J. P., and Struewing, J. (2007).Genome-wide association study identifies novel breast cancer susceptibility loci. Nature Journal of Cell infection 447(7148)

Narod, K. and Offit, P. O. (2010). Stroma in breast development and disease. Semen Cell DevBiol 21(1)

National Bureau of Statistics (2014).Annual epidemiology report. Abuja, Nigeria.

Ogundioe, L. and Obinna, C. (2008). Research and ICTs relevance in innovation diffusion. The Nigeria journal of communication. Vol. 5(2)

Olapade, M. (2004), Nigeria Association of Women Journalists in Enugu.Journal of Communication, 3(2)

Oldenburg, J. E., Trute, D., White, M. C. and Southey, F. (2007). Distinct molecular pathogeneses of early-onset breast cancers in BRCA1 and BRCA2 mutation carriers: A population-based study. Cancer Res 59(8)

Patel, A., Pathak, Y., Patel, J. and Sutariya, V. (2018). Role of Nutritional Factors in Pathogenesis of Cancer. Journal of Food Quality and Safety, Volume 2, Issue 1, pages 27-36.

Penhoet, D. P., Albarracin, A., Lopez, V., Valero, C. I. and Amos, A. M. (2005). Clinical and pathologic characteristics of patients with $B R C A$-positive and $B R C A$-negative breast cancer. J ClinOncol26 (26)

Shelps, G. (2013). Comprehensive analysis of common genetic variation breast cancer risk in the NCI breast and prostate cancer cohort consortium. Hum Mol Genet 19(19)

Steve, K. (2009). Circadian regulation of molecular, dietary, and metabolic signaling mechanisms of human breast cancer growth by the nocturnal melatonin signal and the consequences of its disruption by light at night. J Pineal Res51 (3).

Syawalina, S., Santosa, H., and Rahayu, S. S. (2020). Education Relation, Number Of Children And Acceptance Of KB Information With Pregnancy Due To Unmet Need KB In Pregnant Mother In Binjai Health Center City In 2019. Budapest International Research in Exact Sciences (BirEx) Journal, Volume 2, No 1.

World Health Organization (2004). The World Health Report 2002: Reducing Risks, Promoting Healthy Life.Geneva

World Health Organization (2012). People working with people in education for health. Manual for Health Education in Primary Health Care. Geneva

World Health Organization (2014). Education for health. A Manual on Health Education in Primary Health Care. Geneva

Zhang, K. (2016). Misleading presentation of breast cancer in popular magazines. EffClinPract 4(2) 